Próceres civiles de la República.

\title{
Felipe Santiago Estenós, Secretario General del Libertador Bolívar.
}

Medio siglo de nuestra historia, en la que tuvo tan destacada actuación, se confunde con la vida prócer de Felipe Santiago Estenós, primero Secretario del ejército patriota expedicionario en el Centro, luego Secretario Generàl del Libertador Bolívar, después Vocal fundador de la Corte Superior de Arequipa, miembro del Consejo de Estado, Vocal de la Corte Suprema de Justicia, Ministro del Interior durante el primer gobierno del Mariscal Castilla y finalmente Fiscal de la Nación.

Nació Estenós en Arequipa en I797 .Fué hijo legítimo de don Pedro Estenós y de doña María del Carmen Corrales y León radicados en esa ciudad. Gobernaba entonces al Perú don Ambrosio de O'Higgins, Marqués de Osorno, y atravesaba el Virreinato la inquieta etapa de transición entre el fidelismo colonial y la efervescencia doctrinaria, alentada por la propaganda clandestina de las ideas liberales. La infancia de Estenós coincide con las perspectivas promisoras,-altibajos de angustias y esperanzas para la causa de la libertad. Todavía se recordaba con horror, en Arequipa, la ferocidad con que algunos lustros antes había sido trágicamente reprimida la sublevación indígena de José Ga- 
briel Condorcanqui, extendida por casi toda la región del sur. Con el retraso consiguiente a la dificultad de las comunicaciones, llegaban a Arequipa, ya en tiempos del Virrey Abascal, las noticias de las conspiraciones que se descubrían y debeleban en Lima por la sagacidad, a veces enérgica y a veces ingeniosa, de la primera autoridad. Comentábase en casa de las familias arequipeñas distinguidas la forma como, en I809, había sido descubierta la conspiración limeña de los hermanos Mateo y Remigio Silva. Elogiábase la prudencia del Virrey para conjurar la conspiración que se tramaba en la Escuela de Medicina, bajo la dirección de Hipólito Unánue y con la complicidad de los profesores, todos ellos amigos personales de. Abascal, a cada uno de los cuales llamó a su despacho, limitándose a informarles de que estaba enterado, en detalle, de sus actividades subversivas. Motivo de agudas glosas era la táctica empleada por Abascal para desbaratar otra conspiración planeada en la celda del padre Segundo Antonio Carrión, en el convento de San Pedro. El Virrey envió a sus agentes para que, en las primeras horas de la thadrtgada, esperarana $a$ los conspiradores en la portería dép convento y conformes íban saliendo, uno a uno, los saludaran en su nombre, iluminándoles la cara con una linterna de mano para conocerlos. Y se elogiaba también, sin reservas, la prudencia de Abascal, para no intervenir, en forma alguna, en el Convictorio Carolino, dirigido entonces por Toribio Rodríguez de Mendoza y convertido en un epifoco de la acción liberal. En ese ambiente, vivido por Lima, y reflejado en Arequipa, transcurrió la infancia de Felipe Santiago Estenós.

Catorce años tenía Estenós cuando sintió en su espíritu la primera gran emoción patriótica: la noticia de la sublevación de Tacna, en I8ri, acaudillada por el prócer Zela. Se había tramado un movimiento general en Arequipa, Mo- 
quegua, Tacna y Tarapacá que debía estallar en el momento en que los ejércitos argentinos que venían avanzando por el Alto Perú hicieran su aparición por el Desaguadero. Pero los argentinos fueron derrotados en Huaqui. Arequipa, Moquegua y Tarapacá no secundaron el movimiento. Fracasó, por eso, la revolución de Tacna. Condenado a muerte, Zela obtuvo, mediante activas influencias de sus familiares y amigos, que se le conmutara la pena por diez años de presidio en Chagres, Panamá, donde murió antes de cumplir la condena.

Estenós, todavía adolescente, vivió también en Arequipa las horas de inquietud revolucionaria. En I8I 3 Tacna vuelve a sublevarse con los hermanos Pallardelli y José Gómez, en conexión con los patriotas del Alto Perú y los conspiradores de Arequipa. En la cindad del Misti, el Intendente Moscoso envió a combatir a los revolucionarios a las tropas al mando de don José García de Santiago y apresó, entre otros, a don Manuel José de Rivero, sindicado como jefe de los conspiradores arequipeños. La derrota de los argentinos en Vilcapuquio frustró

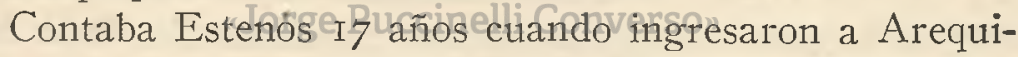
pa las tropas del cacique indio y brigadier don Mateo $\mathrm{Pu}^{-}$ macahua que se había sublevado en I8I4. La revolución adquirió vastas proyecciones. En el Cusco, donde estalló el movimiento el 3 de agosto de ese año, se formó una Junta de Gobierno, presidida por Pumacahua e integrada por el coronel don Domingo Astete y Tomás Moscoso. Al frente de un improvisado ejército Pinelo y el cura Ildefonso Muñecas habían llegado hasta La Paz y capturado la ciudad. Los hermanos Angulo y Hurtado de Mendoza avanzaron hasta Huamanga. Y Pumacahua con el grueso de su ejército entró triunfalmente en Arequipa. La juventud arequipeña, plena de fervor patriótico se plegó a la causa revolucionaria. 
La mayor parte de los jóvenes, entre ellos el poeta Melgar, se alistaron en el ejército patriota y quienes no podían hacerlo, en razón de su menor edad, como Estenós, fueron activos propagandistas de las ideas liberales con una decisión que no lograron amenguar ni la derrota de la revolución, ni el fusilamiento de Melgar en el mismo campo de batalla de Umachiri, ni el descuartizamiento, ni la decapitación del anciano Pumacahua en la plaza de Sicuaní.

Terminados sus estudios escolares, Felipe Santiago Estenós se dirigió a Lima, matriculándose en la Universidad Mayor de San Marcos, para seguir su carrera de abogado. Todavía Arequipa no tenía Universidad, la que sólo se estableció el I2 de setiembre de 1845. En I82r terminó, con éxito, sus estudios profesionales, obteniendo su grado e incorporándose al H. Colegio de Abogados el 27 de agosto de ese mismo año. Un mes antes se habían realizado, en esta capital, sucesos trascendentales: la evacuación de la ciudad por las tropas realistas al mando del Virrey La Serna, el ingreso del ejército libertador con San Martín, la convocatoria del ejército argentinota una Asamblea de Notables para que decidiera la situąión yslánsolemnevproclamación de la independecia, ante el Cabildo Abierto, el 28 de julio de I82 I.

Desde entonces Estenós presta utilísimos servicios a la causa de la libertad. Se enrola en el ejército patriota que actuaba en el centro y es nombrado Secretario del General en Jefe, don Juan Antonio Alvarez de Arenales, que había venido al Perú junto con la expedición libertadora de San Martín; que luego había marchado desde Pisco hasta Junín, sublevando a los pueblos del tránsito; que en Cerro de Pasco logró derrotar a las tropas españolas, capturando a su jefe el brigadier O'Reilly, junto con tres banderas y cinco estandartes; y luego se encargó de mantener la autoridad del Protectorado, tanto en la sierra como en la costa del centro 
del Perú. Jefe del Estado Mayor era el Coronel de Artillería don José N. Borgoño (r). La permanencia de Estenós en el ejército del centro va a trazar, en parte, el destino de su vida. Acompaña al General Arenales en sus visitas periódicas por la región. En una de ellas se detiene en la Hacienda de Loreto Humaya, en la villa de Huaura, cuyo acaudalado dueño era el español don Benito Cerreño, casado con doña Francisca Mares, natural de Lima. De ese ejemplar matrimonio nacieron en Lima, Vicenta y en esa hacienda, la niña María Juana el 25 de marzo de I8r2, bautizada dos días después, en la Capilla del fundo, por el doctor don Gregorio Mier, Cura Vicario del pueblo de San Bartolomé de Huacho. Fué su padrino don Pedro Espejo y testificaron el acto don Domingo Cerreño y don José Vargas. Veinticinco años tenía Estenós y diez María Juana Cerreño cuando conoció a Vicenta, en la hacienda Humaya, en I822. Ocho años más tarde unirían sus destinos para siempre.

Después de la Conferencia de Guayaquil, en la que no pudieron armonizarse los espíritus dispares de Bolívar y San Martín, este último regresó decepeionado a Lima, y convocó a elecciones para el Congreso Constituyente, realizadas en agosto de I822, mediante el tema indirecto de los colegios electorales. Estenós fué elegido entonces Diputado por la Provincia de Arequipa, su tierra natal, por haber obtenido la pluralidad absoluta de sufragios, expidiéndole la respectiva credencial el 2 de agosto de 1822 en Lima, (2) los persone-

(1) Tenemos a la vista el original del documento histórico que dice así: "En el presupuesto de los SS. Jefes, Oficiales y demás individuos que componen el Estado Mayor del Ejército del Centro, se halla comprendido el S. D. D. Felipe S. Estenós como Secretario del Sr. Gral. en Jefe D. Juan Anto. Alvares de Arenales y como tal pasó revista de presente en Lurín el día 11 de noviembre de 1822. (firmado) Jefe de Estado Mayor, Coronel de Artillería don José M. Vorgoño".

(2) "Al S. D. Felipe Santiago Estenós.-Tenemos el honor de poner en manos de $\nabla$. S, el poder que la Mesa Preparatoria pa las elecciones de Diputado por la Prv. de Arequipa ha extendido a favor de V. S., en virtud 
ros de la Mesa Preparatoria del Congreso don Benito Lasso y don Pedro de la Torre. El Congreso se instaló el 20 de setiembre de 1822 . Cuerentiseis representantes -entre ellos 26 eclesiásticos y I 3 extranjeros- lo integraban. El Protector San Martín les tomó juramento en la Iglesia Metropolitana y luego dimitió sus poderes, embarcándose en el buque de guerra Belgrano, con rumbo a la Argentina. El Congreso designó de su seno, para que se encargara del Poder Ejecutivo, a una Junta, presidida por el General José de la Mar, diputado por Puno, que fué derribada por el motín militar del Balconcillo, a raíz del desastre de la primera campaña de intermedios. Estenơs compartió entonces sus funciones legislativas con sus deberes patrióticos en el Ejército del Centro.

El 4 de marzo de I823, siendo Presidente de la República el General Riva Aguiero, fué nombrado Estenós Asesor Jurídico de la Presidencia del Departamento de Lima. Atravesaba el país entonces una crítica situación. Los patriotas no supierboâprovechar sus śxitos militares en la segunda campañarde intermediosontes realistas, con Canterac, recapturaron Lima, en la que permanecieron los meses de junio y julio de I823, abandonándole luego, por su propia voluntad, no sin antes dejar huella imborrable de su crueldad en el callejón de Petateros fusilando, después de haberlo torturado inictiamente, al pescador José Olaya por haberse negado heroicamente a revelar la misión que los patriotas le habían confiado. Destituído. Riva Agüero por el Congreso, pretendió dualizar en Trujillo el Poder Legislativo y fracasó en ese empeño. Surgió entonces en el país una corriente de opinión favorable a la venida de Bolívar al

de haber recaído en su persona la pluralidad absoluta de sufragios pa Diputado provisional, en clase de suplente por ntra. prova.-Dios gue a V. S. Lima y agto. 2 de 1822. (firmado) Benito Laso.-Pedro de La Torre". 
Perú. La patrocinaban, entre otros destacados elementos, José Joaquín Olmedo, Felipe Santiago Estenós y José Faustino Sánchez Carrión.

Estenós comprendió la magnitud de la obra histórica del Libertador Bolívar y fué, desde entonces, el más decidido defensor de su política. Bolívar, a su vez, supo àpreciar en Estenós a uno de sus más eficientes, capaces y leales colaboradores. El 22 de enero de 1825, el Libertador lo nombró Asesor del Tribunal del Consulado, y el r..$^{\circ}$ de abril de ese mismo año le otorgó un cargo de excepcional confianza: lo designó su propio Asesor en la campaña del Alto Perú. Ese mismo día, en el apogeo de su gloria, auroleada con los signos epónimos de Junín y Ayacucho, Bolívar inició su gira triunfal por el sur del Perú. Estenós lo acompañó en todo su recorrido. Partiendo de Lima, la comitiva siguió por Lurín, Cañete, Pisco, Ica y Arequipa siendo colmada de homenajes. Renuncia, en esta última ciudad, el cargo de Secretario del Libertador, el coronel José Gabriel Pérez, y entonces Bolívar nomibracensua reemplazo, con el título de Secretario General al doctor Felipe Santiago Estenós, especificando en el decreto de nombramiento, firmado por el Libertador el 9 de junio de I825, que Estenós "será el órgano, de todas sus comunicaciones con todas las autoridades de la República y gozará de las mismas atribuciones que tenía quien venía ejerciendo tan importantes funciones" (3). Estenós resulta entonces un Ministro sin cartera. Nexo entre el Libertador y la República, es, después del propio Bolívar, el hombre que concentra en sus manos el mayor poder politico.

Días ảntes, el 2 de junio, el Libertador había creado la

(3) El decreto del nombramiento del doctor Estenós como Secretario General del Libertador Bolívar, se publicó en "La Gaceta de Lima", N.? 9, Tomo VIII. 
Corte Superior de Arequipa y nombró a Estenós uno de sus Vocales fundadores, en unión de los doctores José Sánchez de la Barra, Felipe Antonio de la Torre, J. Cuadros, Mariano Luna, Mariano Blas de la Fuente y Mariano Esteban de la Llosa. Estenós asistió a la instalación de la Corte, asumió su cargo, pero en seguida solicitó y obtuvo la licencia correspondiente para proseguir, acompañando a Bolivar, en calidad de Secretario General en su gira por el sur del Perú. Continuó el viaje por Cangallo, Oropesa y llegó al Cusco. Los homenajes que la sociedad cusqueña tributó al Libertador fueron tan extraordinarios como los que había recibido en Arequipa. Quiso Bolívar dejar en el Cusco una huella perdurable de su paso y por eso encargó a Estenós la redacción de los decretos correspondientes, firmados por el Libertador y refrendados por su Secretario General, creando allí el Colegio de Ciencias y Artes, el Colegio de Educandas, reorganizando da Universidad y fundando el Hospital del Cusco. De la antigua capital imperial de los Incas pasaron el Libertador y su comitiva a Puno, a orillas del lago legendario y prosiguieron hasta la ciudad de La Paz. Allí nació Bolivia, la nueva república que debía perpetuar el nombre del Libertador y cristalizar, en efímero ensayo, sus ideales políticos. De la Paz la comitiva prosiguió por la fabulosa región minera de Potosí, Chuquisaca que más tarde llevaría el nombre del apostólico Sucre y Cochabamba. Descendió luego hacia la costa, siguiendo el mismo camino de las recuas cargadas de los minerales que se exportaban para la Península Ibérica, en los días del coloniaje, y, llegando el 20 de setiembre a la ciudad de Tacna en donde, años atrás, había lanzado Zela el primer grito de libertad, secundado después, allí mismo, por los hermanos Pallardelli. De Tacna, Bolivar y Estenós se dirigieron a Arica, puerto principal en el corregimiento del mismo nombre y allí se em- 
barcaron a bordo del "Chimborazo" que los condujo a Chorrillos. Lima tributó entonces al Libertador un recibimiento apoteósico. Gobernaba al país el Consejo de Gobierno, nombrado por el propio Bolívar, presidido por el General don José de la Mar e integrado por don Hipólito Unánue, y don José Sánchez Carrión. Dos días después de la llegada de Bolívar a Lima, renunció La Mar y fué reemplazado en la Presidencia del Consejo por el Mariscal Santa Cruz, nombrándose a Pando, Ministro de Relaciones Exteriores, a don José de Larrea, Ministro de Hacienda y continuando Unánue al frente de la Cartera de Justicia y de Asuntos Eclesiásticos. Bajo la aparente autoridad de este Consejo, Bolívar era, en realidad, el gobernante del Perú.

La gira triunfal de Bolivar, por el sur del Perú, había servido para unirlo aún más estrechamente con Estenós. "Entre ambos personajes - afirma acertadamente el Dr. Oscar Barrenechea y Raygada, en un estudio recientemente publicado- se estableció esa compenetración espiritual que sólo nace del continuo trato de comunidad de aspiraciones, cuando las alienta un mismo y noble, ideal. Estenós fué el más fiel colaborador y consejero de Bolívar y el depositario de sus más íntimos secretos y de la grandiosidad de sus vastos planes. De nadie puede decirse, con más justo título, que fué un auténtico prócer bolivariano" (4).

El I7 de febrero de 1826 el doctor Felipe Santiago Estenós fué nombrado Vocal titular de la Corte Suprema de Justicia de la República, expidiéndole el título el Consejo de Gobierno. Contaba entonces 29 años de edad y fué el más joven de los magistrados que integró el tribunal supremo, que había sido creado por decreto de Bolivar del I9 de di-

(4) Oscar Barrenechea y Raygada, "Los Estadistas Peruanos, herederos de la tradición bolivariana y los Congresos Internacionales Americanos reunidos en Lima".- "El Comercio", 8 de mayo de 1938. 
ciembre de 1824 - diez días después del triunfo de Ayacucho- nombrando el 22 del mismo mes, como Vocales fundadores a los doctores Manuel Lorenzo Vidaurre y Encalada, Francisco Valdivieso, José Cavero y Salazar, Fernando López Aldana e Ignacio Felomeque, y Fiscal, al doctor José María Galdeano. La Corte Suprema de la República se instaló solemnemente el 8 de febrero de 1825 . El doctor Estenós prestó el juramento de estilo el 20 de febrero de 1826 (5).

Empieza a opacarse entonces la estrella política del Libertador. Arrecia en el Perú y en la Gran Colombia la oposición contra sus ideas y sus métodos de gobierno. Ese temperamento se marca en las elecciones realizadas en $1826 \mathrm{pa}-$ ra estructurar el Parlamento. Se incrementa día a día la legión de prosélitos en el movímiento antibolivariano que acaudilla Luna Pizarro, diputado por Arequipa, a quien se le ofreció nuestra Plenipotencia en México y, al no aceptarla se le desterró en julio de ese mismo año. Las actitudes subversivas de Tacna, Ica y Camaná provocaron medidas gubernativas de singular energia para mantener el orden público. Necochéa y Guisse fueron desterrados. Y el fusilamiento del teniente Manuel Aristizábal vino a enconar aún más las pasiones políticas. La reacción antibolivariana estalló, también en la Gran Colombia. El patriota Arismendi, uno de los próceres de la independencia venezolana, provocaba allí asambleas populares contra Bolívar. El General Córdova, uno de los héroes de Ayacucho, se sublevaba contra el Libertador, quien, contrariando las súplicas de sus adic-

(5) República Peruana.-Sello tercero para los años de 1825 y 1826.Certifico qe el día 20 del presente mes y año el S. D. D. Felipe Santiago Estenós prestó el juramento de estilo en esta Suprema Corte de Justicia pa Vocal de ella, en virtud del Título expedido $p^{n}$ el Excmo. Consejo de Gobierno y fué admitido al uso y exercicio de su Empleo en dicho día; y mediante a haber autorizado el acto $\mathrm{p}^{\mathrm{n}}$ enfermedad del Secret doy la presente en Lima $y$ febrero 25 de 1826. (firmado) Luis Salazar". 
tos peruanos, se vió precisado a abandonar nuestro país para dirigrise a Colombia, embarcándose en el bergantín "Chimborazo" que lo condujo a Guayaquil. Se le separaban los amigos en cuya lealtad había confiado y muy pocos entonces le permanecen fieles. Sólo Sucre, Santa Cruz, Estenós y unos cuantos más siguen rindiendo culto a su credo bolivarista, en sus horas más críticas, en sus últimos meses de la estada del Libertador en el Perú y cuando, después de su alejamiento de nuestra patria todas las pasiones políticas vuelcan su baba venenosa contra Bolívar. Sucre, para evitar mayores derramamientos de sangre, dimite la Presidencia vitalicia de Bolivia y se destierra, decepcionado, a la Gran Colombia. Santa Cruz, desligado de sus comprimisos políticos por el propio Bolívar, quien le anuncia en una carta su decisión de no volver más al Perú, acepta la presidencia de ntiestro país y colabora con los enemigos del Libertador. Estenós se mantiene irreductible. Su lealtad hacia Bolivar no conoce límites ni en el espacio ni en el tiempo.

En 1830, ebdoctortEelipel Santiago Estenós contrajo

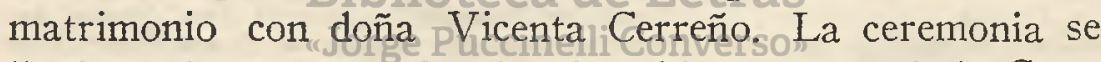
llevó a cabo con exepcional solemnidad en la Iglesia Catedral de Lima. Era la primera vez, en la República, que la Catedral se usaba para ceremonias nupciales. Otorgó la licencia respectiva, en mérito de la elevada posición social de ambos contrayentes, el Dean de la iglesia metropolitana y gobernador eclesiástico del Arzobispado, doctor Francisco Javier Echague. Bendijo la unión el canónigo penitenciario de la misma iglesia, doctor Jorge Benavente. Testificaron el acto, los señores José de Larrea, Ministro de Hacienda y doctor Manuel Dávila, y las señoras doña Ignacia Novoa y doña Antonia Noriega (6). Ninguno de los padres de los

(6) En el Libro de Partidas Matrimoniales de la Parroquia del Sagrario de la Catedral-hoy Basílica-de Lima, correspondiente al período com- 
país y nombrando por Lima al doctor Manuel Lorenzo Vidaurre, por La Libertad al doctor Justo Figuerola, por Arequipa, al doctor Nicolás de Araníbar, por Ayacucho al Dr. Mariano Alejo Alvarez, por Puno al Dr. Santiago Corbalán y por Junín al Dr. Evaristo Gómez Sánchez. Quedaron entonces cancelados los nombramientos de los Vocales doctores Felipe Santiago Estenós, José María Galdeano, Fernando López Aldana y Manuel Vicente Villarán, quienes se reunieron en sesión plenaria el 23 de agosto, al día siguiente de la trascripción del decreto, y acordaron dejar constancia de su protesta en guarda de sus derechos.

La oposición implacable contra el gobierno de Gamarra lo acusó de haber atentado contra el Poder Judicial para despojar de sus cargos a los miembros de la Corte Suprema que no eran adictos a su gobierno. Alguien creyó ver, en esa medida, una expresión antibolivarista, ya que todos los magistrados cancelados habían sido nombrados por el Libertador. No es admisible esta opinión porque precisamente el gobierno de Gamarra, comprendiendo los altos merecimientos jurídicos del doctor Estenós, y por decreto firmado el I. ${ }^{\circ}$ de febrero de 1832 lo restituyó a la Corte Suprema, nombrándolo su Fiscal interino (8). El I2 de abril de ese mismo año, era nombrado Prefecto del Departamento de Junin, uno de los cargos más importantes de la República, en ese entonces (9).

Los acontecimientos políticos se precipitaron en el país.

(8) "República Peruana.-Casa del Gobierno, en Lima, a 1.9 de Febre. ro de 1832.-Decreto: Estando completo en la Spma. Corte de Jtea. el número de Vocales que señala la Constitución y deviendo nombrarse por separado un Fiscal que sustituya al Dr. D. Manuel Pérez de Tudela, mientras desempeñe el Ministerio de Hacienda so eonfiere provisionalmente dicho eargo al D. D. Felipe Santiago Estenós, por coneurrir en él las calidades necesarias pa su ejercicio.-Comuníquese a quienes corresponda. Una rúbrica del Presidente de la República".

(9) "República Peruana.-Casa del Gobierno, en Lima, a 12 de abril de 1832. Teniendo en consideración $\mathbf{S . ~ E}$. las recomendables circunstancias 
A Gamarra sucedió Orbegoso en el gobierno. Las conspiraciones contra él eran continuas, a tal punto que el Presidente, incapaz de contenerlas, presentó ante la Convención su renuncia del mando supremo, la cual no fué aceptada. Una virulenta campaña periodística, amparada por la libertad de la prensa, la crisis financiera que mantenía impagos a los servidores de la Nación y los ascensos militares prodigados fuera de la ley, aumentaron la impopularidad de Orbegoso. Mientras tanto Gamarra, desterrado en el Altiplano, alentaba las ambiciones políticas de Santa Cruz para formar la Confederación Perú-Boliviana. Una revolución gamarrista, estallada en Puno y propagada en Arequipa, obligó al Presidente Orbegoso a ponerse al frente de sus tropas y marchar al sur a combatirla, dejando el gobierno en manos del Conde deVista Florida. Poco después Salaverry, que se había proclamado en el norte Jefe Supremo del Perú entraba triunfalmente a Lima.

La situación del país era gravísima. Deseoso Salaverry de proceder con acierto en sus resoluciones gubernativas, aprovechando las tuces y pa experiencia de los ciudadanos que, por "su sạber y versación en los" negocios públicos, podían prestársela, y con el propósito de suplir la falta de Poder Legislativo, cré el 15 de junio de 1835 , un Consejo

que reune U. de probidad, ilustración y amor al país, se ha servido nombrarle Prefecto del Departamento de Junín por renuncia del que obtenía este destino.

S. E. cree que no denegará Ud. sus servicios a la Nación, cuando se los exije estimándolos necesarios en beneficio de un departamento digno de tener a su cabeza a un ciudadano como V. Tengo la satisfacción de comunicarle a U. suseribiẻndome su atento servidor. (firmado) M. I. Vidaurre.

Al S. D. D. Felipe Santiago Estenós.

Certifico: que a fjs. 222 del Libro en que se sientan los Juramtos. de los señores vocales, prefectos y demás jueces, consta que el Sr. Dr. Dn. Felipe Santiago Eistenós, Prefecto interino del Departamento de Junín, prestó el juramento de estilo, en esta Corte Superior de Justicia para el servicio de este empleo hoy día de la fha.-Lima, abril veinte $y$ seis de mil ochocientos treinta $y$ dos. (furmado) Luis Salazar.

Tomóse razón en esa admón. gral. del Departamento de Junín.-Cerro, mayo 26 de 1832. (Firmado) Parra. (Otra firma) Onerguí". 
de Estado. Se componía de 24 Vocales y Estenós fué designado uno de ellos. "El gobierno - afirmaba su personero don M. Ferreyros al doctor Estenós, en la nota trascriptoria de su nombramiento- ha concebido grandes esperanzas con la institución de esta Asamblea y que ninguno de los electos le rehusará sus servicios siendo incapaces de traicionar su patriotismo, especialmente en unas circunstancias en que la Nación se los exije con imperio". El Consejo de Estado se instaló a las Io de la mañana del 28 de julio de ese mismo año, en el Salón de Recibo del Palacio de Gobierno, bajo la presidencia del Jefe Supremo General Salaverry y con asistencia de todos sus miembros. Ellos eran el Arzobispo de Lima, el Presidente de la Corte Suprema, Contador General de Valores, Director General de Aduanas, Administrador General de Correos, Director de Minería, Administrador del Consulado, Dean de la Catedral y doctores José Ignacio Moreno, Francisco Javier de Luna Pizarro, Manuel Salazar y Baquíjano, Felipe Santiago Estenós, Francisco Moreyra, Ignacio Ortiz de Zevallos, Manuel Vicente Villarán, Francisco Lopez Aldana, Juan M. "Galdeano, Juan Raymundes, Lucío Villanivar, Lucas Pallicer y Juan Pablo Fernandini. En octubre de ese mismo año, por haber pasado don Juan Bautista de Lavalle a ocupar la Presidencia del Consejo de Gobierno, el doctor Estenós fué nombrado Prefecto del Departamento de Lima (IO). Meses atrás, en

(10) “R. P. Palacio de Gobierno, en Lima, a 13 de oetubre de 1835. Sr. Habiendo el señor don Juan Bautista de Lavalle pasado a ocupar la Presidencia del Consejo de Gob.' se ha servido nombrar este a V. Prefecto del Departamento de Lina, por concurrix en la persona de V. S. los requisitos necesarios para desempeñar satisfactoriamente ese destino.-Tengo el honor de repetirme de V. S. muy atento servidor (firmado) M. Ferreyros,

Al Sr. D. D. Felipe Santiago Estenós.

"Lima, oct. 14 de 1836.-Cireúlese a los sub-prefectos de las provincias y contéstese.-Estenós.-Mariano Ant? Zevallos, Secretario". 
mayo de 1835 , había culminado en esta capital la audaz aventura de la cuadrilla de bandoleros que, encabezada por el negro León Escobar, se apoderaron de la ciudad, tomaron Palacio de Gobierno y le impusieron un cupo de 5.000 pesos al vecindario, reduciéndolo luego, ante la súplica de los vecinos, a 2,500 pesos que fueron pagados de inmediato, retirándose entonces los forajidos satisfechos de su botín. Urgido por las contingencias y necesidades de la campaña, Salaverry había abandonado Lima, instalando su cuartel general en Ica y dejando encargado del Ejecutivo al Coronel Angel Bujanda.

Arequipa es el escenario donde termina la resistencia salaverrista contra el proyecto de la Confederación PerúBoliviana. El efímero triunfo de Uchumayo se liquida tres días más tarde, el 7 de febrero de 1836 , en Socabaya. Y una segunda descarga del pelotón de fusilamiento, en la plaza de Armas de Arequipa, apaga la vida fervorosa del más joven de los Presidentes deloPerúa de Letras

Establecida lar Confederación Peru-Boliviana, el mariscal Santa Cruz entra triunfalmente a Lima el 23 de agosto de I836 y asume el poder con el título de Protector Supremo. Una antigua amistad, cimentada en los días gloriosos de Bolívar, vinculaba estrechamente a Santa Cruz con Estenós. El Mariscal sentía por Estenós la misma predilección afectuosa que le tuvo el Libertador. Ambos reconocían los méritos, !a capacidad jurídica y la austeridad irreductible del ilustre arequipeño. Por eso el Protector Santa Cruz, una vez despuẻs de haber asumido el Gobierno Federal nombra al doctor Felipe Santiago Estenós, Vocal titular de la Corte Suprema de Justicia. Refrenda este nombramiento el Ministro del Interior doctor José María Galdeano, uno de los 
antiguos compañeros de Estenós en el más alto tribunal de justicia, así como en el fervor bolivariano (II).

Dos expediciones chilenas atacan la Confederación, con la ayuda de destacados militares peruanos. La primera de ellas fracasa en Paucarpata, pero la segunda tiene rotundo éxito en Yungay. Disuelta la organización federal, Gamarra asume el mando supremo del Perú e inicia su gobierno ejerciendo represalias contra todos aquellos que hubieren prestado servicios al régimen fenecido aun cuando no hubieran tenido ninguna actuación política. Santa Cruz y Orbegoso fueron declarados traidores a la Patria por el Congreso de Huancayo. Se borró del escalafón del ejército a cuantos jefes y oficiales hubieren servido al sistema federal. Se destituyó de sus cargos/a los servidores civiles, privándoles de sus goces y derechos. El Poder Judicial fué totalmente reorganizado en 1839 , año de la Convención de Huancayo. El doctor Estenós cesó entonces en el titularato de su Vocalía en la Corte Suprena, cargo que volvió a ocupar, interinamente, ceni nútiples coportunidades posteriores; a partir del 20 de febrerode 1845 , en reemplazo del doctor Matías León; a partir del 27 de agosto de 1849 , por nombramiento expedido por el Mariscal Castilla, en reemplazo

(11) "Estado Nor-Peruano.-Palacio Protectoral, en Lima, a 4 de octubre de 1836.-Ministerio del Interior.

Al Sr. Dr. Dn. Felipe Santiago Estenós.

Con esta fecha digo al Sr. Presidente del Supremo Tribunal de Justicia lo que sigue: "Siendo el nombramiento de cesantes en los empleos que vacares, o hubieren vacado, tan conforme a principios de justicia, como conveniente al erario nacional, resuelve S. E. que el Sr. Dr. D. Felipe Santiago Estenós pase a servir a ese Tribunal la plaza que hay vacante, con el sueldo que corresponde a sus destinos, cesando en el despacho, el vocal interino que actualmente la obtiene". I de orden de S. E. el Supremo Protector, tengo la complacencia tie trascribirlo a V. S. para su inteligencia y satisfacción, suseribiéndlome su muy atento servidor (firmado) José Ma Galdiano.

Certifico que el Sr. D. D. Felipe Santingo Estenós tomó posesión, en esto día, de su empleo de Vocal de este Supremo Tribunal, en virtud del supremo decreto inserto en esta nota. I para que surtan los efectos que competan al señor interesado doy esta a su pedimento en Lima y octubre 6 de 1836.(fdo.) Juan Rondon". 
del doctor Maraví de la Cueba, quien ocupaba una curul en el Senado de la República; y a partir del 7 de mayo de 185 I por nombramiento que firmó el Presidente General Echenique, en reemplazo del Dr. Miguel del Carpio; y a partir del 6 de agosto de I853. en reemplazo del Dr. Luis Gómez Sánchez (12). Jurisconsulto notable, hombre de leyes y de estudio, el doctor Estenós puso su profunda versación jurídi-

(12) Los siguientes documentos se relacionan con esos cargos:

"República Peruana. Ministerio de Gobierno y de Relaciones Exteriores. Casa del Supremo Gobierno, en Lima, a 10 de febrero de 1845.-Sr. Presidente de la Excma. Corte Suprema de Justicia.-S. P. Habiendo el Consejo de Estado hecho la respectiva propuesta en terna doble pa proveer interinamente, mientras yo dure en este Ministerio, la plaza de Voeal que se me ha conferido en esa Suprema Corte de Justicia, S. E. el Presidente del mismo Consejo, Eneargado del Poder Ejecutivo, se ha servido, p. dta. de hoy nombrar al Sr. Dr. Dn. Felipe Santiago Estenós que ocupaba el $2^{\circ}$ lugar en la primera terna pa el desempeño de dicha plaza. Tengo el honor de avisarlo a Ud. para conocimiento de ese Supremo Tribunal.-Dios güe a V. S. (fdo.) Matías Lieón".

(firmado) Rudecindo Menacer".

- "República Peruana. Ministerio de Justicia y Negocios Eclesiásticos.Casa del Supremo Gobierno, en Lima, a 27 de agosto de 1849. Sr. Presidente de la Excma. Corte Suprema de Justicia. S. E. Se ha servido nombrar, con esta fecha, previas las propuestas del Consejo de Estado, al Sr. Dr. D. Felipe Santiago Estenôs para que reemplace en ere Supremo Tribunal al Sr. Voeal D. D. José María de la Cuba mientras desempeñe el cargo de Senador. Tengo el honor de comunićr guarde a V. S. (fdo.) M. Ferreyros". elli Converson

Certificado: que hoy día de la fecha se recibió de Vocal de este Supremo Tribunal el Sr. D. D. Felipe Santiago Estenós, en reemplazo del Sr. Vocal D. D. José Maraví de la Cuba, durante su ocupación en la Cámara de Senadores.-Lima, agosto 31 de 1849. Por ausencia del Secrto (fdo.) Luis Salmzar.

El Dr. Estenós sirvió este cargo el mes de marzo de 1851.

- "República Peruana. Ministerio de Justicia y de Negocios Eclesiásticos. Casa del Supremo Gobierno, en Lima, a 7 de mayo de 1851. Sr. Presiden. te de la Exema. Corte Suprema de Justicia. Con esta fecha ha nombrado el Gobierno previa correspondiente propuesta, Vocal interino de ese Supremo Tribunal al doctor don Felipe Santiago Estenós en lugar del propietario doetor don Mliguel del Carpio. Lo que tengo el honor de comunicar a V. S. para conocimiento de esa Suprema Corte y fines consiguientes. Dios gue a V. S. (fdo.) Juan Crisóstomo Torrico".

- "República Peruana. Ministerio de Justicia, Negocios Eclesiásticos y Beneficencia. Lima, a 6 de agosto de 1853. Sr. Presidente de la Exema. Corte Suprema de Justicia. Por decreto de esta fecha se ha servido S. E. el Presidente nombrar Vocal interino de ese Supmo. Tribunal, durante la permanencia en el Senado, del D. D. Luis Gómez Sánchez, al D. D. Felipe Santiago Estenós, considerando en la terna formada por el Consejo do Estado.-Comunícolo a Ud. para su inteligencia y efectos consiguientes. Dios güe a V. S. (fdo.) José Manuel Tirado". 
ca y su austeridad inatacable al servicio de la administración de justicia en el más alto tribunal de la República.

En I842 se desencadenó en Guayaquil en proporciones alarmantes, la epidemia de la fiebre amarilla, también llamado "vómito prieto". Se temió entonces, con razón, que el contagio se propagara hacia el Perú y llegara hasta Lima. En tales circunstancias, el Ministerio de Gobierno puso entonces en vigencia el art. $5 .^{\circ}$ del Supremo decreto del I. ${ }^{\circ}$ de setiembre de 1826 que creaba la Junta Suprema de Sanidad, de carácter mixto, integrada por los médicos y los vecinos más notables, para conjurar alguna emergencia pública. Con fecha I I de noviembre de I 842 se nombró al doctor Felipe Santiago Estenós para que la integrara, en representación del vecindario de esta capital. Merced a las providencias y precauciones dictadas por esta Junta, durante algunos años de activa labor, se logró impedir que la fiebre amarilla hiciera en Lima los mismos estragos que en Guayaquil hacía.

También prestó eịdoctor Estenôs sur colaboración y sus luces en otros cargos noumenosl importantes de la Administración Pública. Fué designado miembro del Colegio Electoral Provincial de la ciudad de Lima, en las elecciones habidas el 29, 30 y 3 I de julio de I842 (I3). El I4 de mayo de

(13) Una circular impresa en agosto de 1842 y que tenemos a la vista, dice: "Los Secretarios del Colegio Electoral de la Parroquia del Sagrario de la ciudad de Lima, capital de la República Peruana, certificamos: que eonsta de las actas de elecciones, que en los días 29,30 y 31 de Julio y 1. o y 2 de agosto del presente año, fueron elegidos para componer el Colegio Provincial, don Melchor Vidaurre por 943 votos, don Martín Garro por 937. don Manuel O. Zevallos por 877, Dn. Francisco Quirós por 875 , Dn. Juan José Pinillos por 858, Mariano Agreda por 855, Manuel Antonio Chávez por 846, $\mathrm{Ig}$. nacio Merino рот 841, Modesto Herce, 822; José Antonio Ugarte, por 818, Dn. Manuel Sagastabeitia por 817, Juan José Landaburú por 687, Manuel Vicente Villarán 655, Manuel Salazar y Baquíjano por 647, Fco. de Paula Moreyra por 631, Dn. Felipe Santiago Estenós por 599, Mariano de la Torre, por 591, José Manuel Tirado por 590; Clemente Ramos por 590, José María Corbacho por 571, Manuel Suero por 567, José Fabio Melgar por 566, José María Sotomayor por 564, José Dávila Condemarín por 552; y para Suplentes, José 
I843, se le nombró Visitador de los Tribunales y Juzgados de la República. Su misión fué la de anotar los vicios susceptibles de remedio en la legislación vigente y aportar los datos seguros e instrucciones exactas para la reforma que demandaba la opinión pública en esa materia y "teniendo en consideración-así decía el decreto de su nombramientoque el principal deber del Grobierno es velar sobre la pronta y exacta administración de justicia como la base principal de la tranquilidad pública y bienestar individual; y que para cumplir tan sagrada obligación se hace indispensable corregir los vicios y abusos introducidos en ella, no menos por efecto de las diferentes y continuas revoluciones que han afligido a la Nación, que por la complicación de los Códigos y de las antiguas y varias leyes revocadas, corregidas y de mil modos alteradas, según los diversos sistemas de Gobierno."

El 6 de mayo de I843, en la época de la anarquía militar, el Supremo Director creó el Consejo de Estado para que lo asesorase en las arduastareas del Gobierno. El Dr. Estenós fué designado entoncescinolide suseconsejeros ( I4).

Alto cargo que desempeñó también el Dr. Felipe Santiago Estenós fué el de miembro del Tribunal de los Siete

de la Puente por 590, José Fernando Santiago por 589, Joaquín Jordán por 582, Sebastián Aliaga por 579; y para su constancia y efectos legales les damos el pte. certificado a 3 de agosto de 1842. (fdo.) Melehor Vidaurre, Francisco de P. Mioreyra.

(14) República Peruana.-Ministerio de Gobierno, Culto y Beneficencia. Palacio Directorial, en Lima, a 23 de mayo de 1843.

Sr. Dn. Dn. Felipe Santiago Esteщós.

Reuniendo V. S. las distinguidas calidades $y$ especiales conocimientos que se requieren para corresponcler a las más altas miras que se propuso el Supremo Gobierno al crear el Consejo de Estado, por decreto de 6 del mes corriente, S.-E. el Supremo Director se ha servido nombrarle Consejero, esperando del patriotismo de V. S. que desempeñará tan honroso como delicado cargo, con el celo y contracción absoltuamente indispensables para organizar los ramos de la administración pública, para emprencler las reformas exigidas imperiosamente por la opinión y para que el Consejo del que V. S. va a ser digno miembro tenga el lustre que le corresponde como al primer cuer. po del Estado.-Dios güe a V. S. (fdo.) Luis G. Sandoval. 
Jueces. Este organismo de casación debía revisar y atender las quejas que los litigantes formularan sobre las funciones ejercidas por los señores Vocales de la Corte Suprema de Justicia, a fin de garantizar su máxima eficacia y de responsabilizarlos en ese ejercicio. Se dispuso por decreto supremo de 16 de mayo de 1848 que los miembros del Tribunal de Siete Jueces fueran elegidos del seno del Consejo de Estado. El 28 de octubre de ese mismo año, la Corte Suprema, representada por los doctores Mariano Alvarez, Justo Figuerola, José Freyre, Benito Lasso y Fco. Javier Mariátegui, expresó su disconformidad con la formación de ese tribunal, ante la posibilidad de que, en lo sucesivo, por los vaivenes de la politica, podrían ser miembros del Consejo de Estado y, por ende, del Tribunal de los Siete Jueces, los mismos que, como clientes, patrones o abogados tuvieren pleitos pendientes ante la Corte o esta hubiera fallado ya en forma adversa a sus intereses o a los de sus patrocinados. "Sería esto-decía ese informe-poner la decisión de s11 honor y de su responsabilidad ehemanos des los que se creen agraviados y presentarle una ecasión des desquite a sus resentimientos".

Felipe Santiago Estenós, prócer bolivariano de la República, no actuó en la política beligerante. Se mantuvo por encima de todos los enconos y de todas las pasiones en l11cha. Su personalidad así cobró mayor prestigio y mereció el respeto de todos los caudillos militares que se sucedieron en el solio presidencial. El Mariscal Castilla quiso captar la voluntad del prócer y Estenós no pudo sustraerse, en I846, a los requerimientos de los negocios públicos. Fué nombrado Ministro de Gobierno el 26 de mayo de 1846 . No pudo ser más enaltecedora para Estenós, la nota que, comunicándole tan honrosa designación, le dirigió el Presidente 
del Consejo de Ministros, don José Gregorio Paz Soldán. "Deseando S. E. el Presidente de la República - le dicenombrar un ciudadano de reconocido patriotismo, honradez y luces para confiarle el Despacho del Ministerio de Gobierno ha fijado su elección en V. S. por creerlo adornado de estas calidades y que hará a su Patria el servicio de aceptar el expresado Ministerio. Decidido S. E. a que la elección que hace no sufra retardo ni dificultades, me previene también que diga a $\mathrm{V}$. S. que es invariable y que mañana se presentará V. S. en el Salón de Palacio a prestar el juramento de posesión, para lo cual se han dado las órdenes correspondientes. Al comunicar a V. S. su nombramiento puedo asegurarle, por mi parte, serme muy grato verme asociado a un patriota que ha prestado servicios a la Nación, desde los primeros días de la Independencia" ( I4a).

Cinco meses estuvo el doctor Felipe Santiago Estenós ejerciendo con brillante éxito y acrisolado patriotismo, el Ministerio de Gobierno que en hora buena le confiara Castilla. Vivía entondes lèDpás dos añosepronisores en que, cerrado el trágico Jperéodocdenlalianarqúáa militar que tanta sangre, dolor y luto costara a la República, se abrían, bajo los signos del Gran Mariscal, una era de paz, constitucionalidad, orden, bienestar económico y progreso que al Ministro Estenós le correspondió asegurar.

En el mes de octubre enfermó gravemente Estenós.

(14 a) La respuesta del Dr. Estenós, fechada el 27 de mayo de 1846 está concebida en estos términos: "Cumpliré con presentarme hoy a prestar el juramento qe la Constiton exige a los Ministros de Estado, supuesto que es invariable la resolución de S. E. el Presidente al encargarme el Despacho del Ministo de Gobierno, según se sirva $\nabla$. S. comunicármelo en su respetable nota de ayer.

No me creo capaz de satisfacer los bien conocidos deseos de $\mathbf{S}$. E. por el rápido progreso del país y aunque este convencimiento debería excusarme ante S. E. de aceptar la elección que por pura bondad ha hecho en mí, sin embargo me creo también obligado por lo que debo a mi Patria, de servirle hasta donde pueda. Procuraré satisfacer los deseos de S. E. seguro de que si lo consigo habré llenado las exigencias públicas". 
Por eso dejó de concurrir a su despacho y presentó la dimisión de su alta investidura. En la nota, fechada el i6 de octubre de 1856 , firmada por el Presidente del Consejo de Ministros, General don José Rufino Echenique y dirigida al Ministro dimisionario, el Gobierno le expresa sus sentimientos por su renuncia y su elocuente aplauso por su gestión ministerial. "Su Excelencia, el Gral. Presidente-dice esa nota-a quien manifesté la muy apreciable nota de V. S., 8 del que corre, me manda contestarle: que habiendo V. S. desempeñado el Ministerio de Gobierno con la más acrisolada honradez y asidua contracción, le ha sido en extremo sensible la separación que solicita; pero que atendiendo a los insuperables motivos en que apoya su renuncia, provenientes del mal estado de su salud, admite la dimisión hecha por V. S. dándole al mismo tiempo las gracias por el acierto y buen desempeño con que ha dirigido el Ministerio durante el tiempo que ha estado a su cargo y asegurándole que el Gobierno queda plenamente satisfecho de su celo y laudableicoliductacen cé cumplimiento de sus deberes" (I5). "Jorge Puccinelli Converso"

Repuesto de su enfermedad, Estenós continuó sirviendo a la República, en el último tercio de su vida. El Gran Mariscal Castilla, que le tenía singular aprecio, desde los días epónimos de Bolívar, lo nombró Vocal del Tribunal de

(15) La dimisión del Ministro Estenós, fechada el 8 de octubre de 1846 y dirigida al Sr. Ministro de Guerra y Marina, está concibida así: "Hoy es el cuarto día que falto al Ministerio por un fuerte ataque de fiebre que me ha tenido sin acción para nada. Los efectos que me ha producido y los síntomas que ia afectan me hacen creer que por muchos días estaré incapaz de contraerme al despacho y como esto perjudica al servicio público y atraería censuras sobre el Gobierno, me es preciso suplicar a S. E. admita la dimisión que hago del Ministerio para que se sirva entregar a otro su Despacho. Muy reconocido a las consideraciones de aprecio con que me ha honrado $\mathbf{S}$. $\mathrm{E}$. he de merecer a $\mathrm{V}$. S. le persuada de mi sincera gratitud y constante respeto". 
los Siete Jueces el io de marzo de I848 (i6) y al año siguiente el 27 de agosto de 1849 Vocal interino de la Corte Suprema de Justicia, en reemplazo del Dr. Maraví de la Cuba que desempeñaba entonces una curul senatorial.

E1 Gobierno creó, en I848, un Consejo Central Directivo de Estadística, con el objeto de adquirir los datos y noticias administrativas necesarias para la mejor dirección de las funciones públicas. El Consejo se instaló en el Salón de Recepciones del Palacio de Gobierno el 6 de agosto de 1848 , aniversario de la batalla de Junín. El Dr. Estenós fué designado uno de sus miembros, "por estar satisfecho-decía la nota trascriptoria de su nombramiento- de que sus conocimientos y patriotismo pueden contribuir a la adquisición de los datos y noticias que en este ramo desea el Gobierno tener para dar mejor dirección a las funciones administrativas, con arreglo al verdadero estado de los pueblos y a sus positivas exigencias". Al mes siguiente, y en desempeño de su cometide, Estenós hizo un yiaje a Arequipa, su tierra natal, a la jue no visitaba desde la gira triunfal con Bolivar (I7).

(16) "República Peruana. Consejo de Estado. Lima, marzo 16 de 1848. Sr. D. D. Felipe Santiago Estenôs.

En sesión de hoy, el Consejo de Estado se ha servido nombrar a V. S. Vocal del Tribunal de Siete Jueces por fallecimiento del D. D. Pascual Antonio Gárate. Lo que me honro en comunicar a V. S. para su inteligencia. Dios güe a V. S. (fdo.) Juan Anto Ribeyro".

(17). El siguiente es el texto del salvo-conducto, concedido al Dr. Estenós para viajar de Lima a Arequipa: "Ministerio de Relaciones Exteriores del Perú. N.9 68. FELIPE PARDO, Ministro de Relaciones Exteriores del Perú, Conceđo libre y seguro pasaporte al Sr. Dr. Dn. Felipe Santiago Estenós, Vocal del Tribunal de los Siete Jueces y Cesante de la Suprema Corte de Justicia, que se dirije a la ciudad de Arequipa. Por tanto ordeno y mando a las autoridades del tránsito no le pongan embarazo alguno en su viaje, sino antes bien le proporcione los auxilios y facilidades que necesitare para verificarlo.-Dado en Lima, a 12 de setiembre de 1848. (fdo.) Felipe Pardo.Lleva un criado. Una rúbrica".

Un sello que dice: "Gobierno Políto de la Prov. Litoral del Callao", a 
En enero de 1849, Estenós en unión de otros vecinos notables de la capital, fué nombrado miembro del Jurado de Imprenta (I8) y el 28 de setiembre đe ese mismo año fué designado Inspector del Instituto Nacional (19) y el I 5 de julio de 1850 lo nombró miembro de la Junta Central de Instrucción (20) en cuyo ejercicio emitió un interesante informe sobre el estado y condiciones en que funcionaban los colegios particulares de mujeres en esta Capital. Este informe es uno de los valiosos puntos de referencia en la historia de la pedagogía peruana. Renunció este cargo el io de setiem-

14 de setiembre de 1848. Permitasele continuar su viaje a la ciudad de Arequipa. (fdo.) Deustua.

Un sello que dice: "Capitanía del Puerto del Callao", a 14 de setbre. de 1848. Puede embarcarse. (fdo.) Carrasco.

Gobierno Político y militar. Tslay, setiembre 18 de 1848. Siga francamente a su destino. (fdo.) Palma.

(18) Una circular impresa en 1849 y que tenemos a la vista dice así: "Los Secretarios del Colejio Electoral de la Provincia de Lima. Certifica. mos: que consta de las actas de elecciones que en los días 17 y 19 del pte. mes fueron elegidos Jurados de Imprenta en primera votación los señores José Francisco Andraca, Manuel Odriozola, Buenaventura Seoane, Ignacio Alareo, Franciseo Chávez, Agustín Fuentes Ghávez, General don Mariano Sierra, Vicente Villanueva, Felipe Santiago Estenós, Melehor Vidaurre, Felipe Orellana, Clemente Ramos, Bartolomé Herrera; Antonio Arenas, Pedro Bueno del Rivero, Joaquín Sáenz, Juan José Moreyra, Casimiro Vera Tudela, Faustino Olaya, Lino Mariano Becerra, Juan José Guerei, Lorenzo Vargas, Pedro Ureta, Francisco Zavala, José Alejandro Dávila, José María Seguín, Francisco Carassa y José Jesús Ayllón y para su constancia y efectos legales, les damos el pte. certificado, en Lima, a 22 de enero de 1849. (fdo.) Manuel Carmelino, Francisco de Paula García, Secretarios.

(19) "Ministerio de Gonbo, Instrucción Pública y Beneficencia.-Lima, setiembre 28 de 1849.

Sr. Dr. Dn. Felipe Santiago Estenós.

Admitida por el Gobierno la renuncia que ha hecho el D. D. José Dávila del cargo de Inspector del Instituto Nacional ha tenido a bien nombrar a $V$. S. con fecha 22 del actual para que lo desempeñe, cierto que lo hará V. S. con el celo que ha mostrado siempre en favor de los establecimientos públicos de la Nación. Lo que comunico a V. S. para su inteligencia y fines consiguientes. Dios güje a V. S. (fdo.) Juan M. del Mar”.

-Por decreto supremo del 31 de enero de 1850 se constituý́ la Junta de Cesantes, nombrando para integrarla a Jos doctores José Dávila Condemarín, Felipe Santiago Estenós, Bernardo Muñoz y Fco. Reyna para la revisión de los expedientes de cesantía, a fin de comprobar si están sujetos a ley.

(20) Esta Junta se organizó con el objeto de reformar la instrucción pública, de conformidad con lo prescrito en el art? 14 del reglamento expedido el 14 de junio de 1850. 
bre de $\mathrm{I} 85 \mathrm{I}$, en atención a sus recargadas labores como Vocal de la Corte Suprema de Justicia (2I).

En I857, el Ejecutivo, en cumplimiento de la ley de la materia, remitió a la Convención Nacional las ternas - en las que figuraba Estenós-para proveer el alto cargo de Fiscal de la Nación. Eran los días decisivos de la revolución de Arequipa, en la que se había atrincherado Vivanco contra el gobierno costitucional de Castilla. Este salió de Lima y se dirigió hacia el sur para combatir a los revolucionarios y asedió a la ciudad de Arequipa durante ocho meses consecutivos, tomándola, al fin, por asalto, después de haberse combatido en las barricadas más sangrientas que recuerda nuestra historia. En tales trances, en Lima, un piquete del ejército, al mando del Comandante Arguedas y del Teniente Carrión, penetró al local donde sesionaba la Convención y la disolvió, antes de que hubiera elegido al Fiscal de la Nación, cargo creado por el art. I 32 de la Constitución vigente entonces y cuya provisión "era tan más necesaria para el prôntỏgirocde los negocios públicos y de los particulares y pararque secigilaira csobresel, cumplimiento de las leyes". Las ternas habían sido enviadas el I I de julio de 1857 y rectificadas el 22 de octubre de ese mismo año. La Convención, empero, no se pronunció sobre ellas. El Consejo de Ministros, encargado del Gobierno por la momentánea ausencia del Mariscal Castilla, expidió el Io de mayo una resolución, en la que "teniendo en consideración que cada día es más imperiosa la necesidad de que funcione

(21) "Ministerio de Gobierno, Instrucción Pública y Beneficencia. Sr. Dr. Dn. Felipe Santiago Estenós. Lima, 10 de setbre. de 1851. Convencido S. E. de que las graves atenciones de U. S. en la Suprema Corte de Justicia le impiden continuar ejerciondo la Inspeeción del Instituto Nacional se ha dignado admitir a V. S. la renuncia que por segunda vez ha hecho en su oficio 5 del corriente del expresado cargo, ordenándome dé a U. S. las gracias a nombre del Gobierno por el celo con que se ha consagrado a su gratuito desempeño. Dios güe a Ũd. (fdo.) Bartolomé Herrera". 
la Fiscalía de la Nación, por cuanto están paralizadas en el Ministerio del Ramo varias demandas de responsabilidad contra las resoluciones de la Corte Suprema de Justicia, así como otros asuntos diversos de interés general, a los que no puede dárseles ningún giro por falta de aquel funcionario; y que no es posible privar por más tiempo a los ciudadanos de las garantías que se les presenta con el juicio de responsabilidad, que, no ha podido llevarse a cabo por la falta expresada", se nombró Fiscal de la Nación al doctor Felipe Santiago Estenós, con cargo de dar cuenta al próximo Congreso Nacional.

En ejercicio de sus altas funciones judiciales, falleció el doctor Estenós, en Lima, el 29 de marzo de 1864, en su casa solariega de la calle de Negreiros. Las exequias de ctuerpo presente se celebraron en la Iglesia de San Agustín. $\mathrm{Y}$ sus restos mortales fueron sepultados en el Cementerio General, Cuartel de San José N. 258 , letra D. (22). "La desaparición de este prócer civil-afirma el Dr. Barrenechea y Raygada enil suicitado estudioetmafcó la pérdida de un elemento que Jperpetuabainell recuerdosodel credo bolivariano, que debía presidir todos los esfuerzos hechos en nuestro país para propiciar la más estrecha solidaridad en los destinos de América.

El Congreso Constituyente de 1931, a iniciativa del parlamentario doctor Gerardo Balbuena, aprobó una ley declarando al doctor Felipe Santiago Estenós prócer de la

(22) En los Libros Parroquiales del Sagrario de la Catedral, donde estân asentadas las partidas de defunción que empezaron a correr en mayo de 1858 y finalizaron on abril de 1874 , a fojas 139 vuelta se registra la siguiente: -

"En Ja ciudad de Lima, capital de la República del Perú, en veintinueve de marzo de mil ochocientos noventicuatro, en la Iglesia de San Agustín se le exequió con Cruz Alta al cadáver del Sr. Dr. Dn. Felipe Santiago Esstenós, Vocal cesante de la Iltma. Corte Suprema, natural de Arequipa, de setenta años de edad y su cadáver fué conducido al Cementerio General, de que certifico. (firmado) Rudecindo Menecer. 
República y ordenando que sus restos fueran exhumados del Cementerio General, donde hasta hoy se encuentran, y trasladados al Panteón de los Próceres, ese santuario laico que la Patria ha erigido para honrar la memoria esclarecida de quienes, como Felipe Santiago Estenós, contribuyeron con las mejores energías de su vida primero a hacerla libre y luego a hacerla grande.

Roberto Mac-Lean y Estenós.

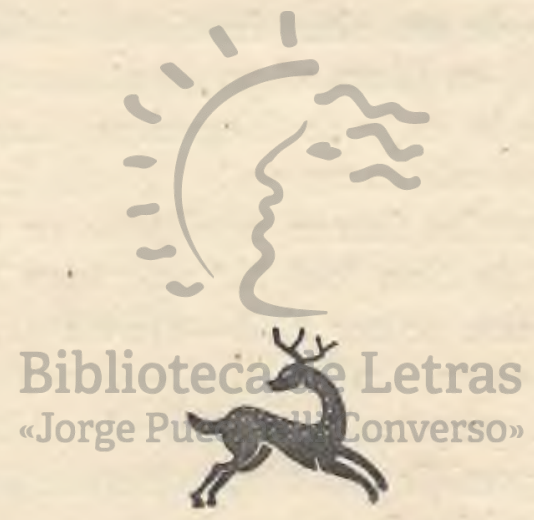

